\title{
Power Converter Based Impedance Emulation of Passive Loads for Anti-Islanding Tests
}

\author{
Aditya Zade, D. Venkatramanan and Vinod John \\ Department of Electrical Engineering \\ Indian Institute of Science \\ Bangalore, Karnataka, India \\ Email: a.p.zade@gmail.com, venkat86ram@gmail.com,vjohn@iisc.ac.in
}

\begin{abstract}
A passive RLC load is essential for conducting anti-islanding tests of inverter based grid connected distributed generator (DG) systems. A variable load is desirable if the tests need to be carried out over a range of operating conditions and on multiple DG based inverters of different ratings. Use of a physical load results in increased cost and space requirements, particularly when the rating of the DG under test increases. This paper presents power converter based impedance emulation technique to actively implement such a parallel RLC load. The dynamic and steady-state response of the load are synthesized using closed loop control of the passive load emulation converter (PLEC), such that the terminal behaviour of the converter matches the passive RLC load characteristics closely. The proposed technique is verified using simulations and experiments that consist of proposed PLEC working in tandem with a current controlled $3 \phi$ DG based inverter on a $5 \mathrm{kVA}$ hardware prototype in laboratory.
\end{abstract}

Index Terms-Anti-islanding, distributed generator (DG), equipment under test (EUT), front end converter, impedance emulation, passive load emulator, passive load emulation converter.

\section{LiST OF SYMBOLS}

$V_{g} \quad$ Per phase grid voltage

$V_{p c c} \quad$ Per phase voltage at PCC

$V_{d c} \quad$ DC link voltage

$I_{d g} \quad$ DG current

$I_{g} \quad$ Grid current

$I_{o} \quad$ Output current of PLEC

$I_{i} \quad$ Input current of PLEC

$I_{F E C} \quad$ FEC current

$I_{d c} \quad$ DC link current

$L_{f} \quad$ Inductive filter of PLEC

$C_{f} \quad$ Capacitve filter of PLEC

$R_{f} \quad$ Damping resistance

$L_{F E C} \quad$ Inductive filter of FEC

$C_{d c} \quad$ DC link capacitor

$S 1 \quad$ Grid side breaker

$S 2 \quad$ DG side breaker

\section{INTRODUCTION}

The number of installations of renewable energy based distributed generators (DG) has rapidly increased owing to

This work was supported by CPRI, Ministry of Power, Government of India, under the project 'Power conversion, control, and protection technologies for microgrid'. decentralization of energy production [1]. A voltage source inverter (VSI) is typically used as a power electronic interface that facilitates DG interconnection with the grid. Antiislanding tests of such a grid connected inverter based DG are essential to evaluate its performance in detecting grid discontinuity [2]. Also unintentional islanding [2]-[4], which is undesirable because of safety concerns, damage to utility equipment and to the DG [5], can be subsequently prevented using such tests of inverter based DG.

As per IEEE Std. 1547-2018, the equivalent circuit model, as shown in Fig. 1(a), is considered for anti-islanding tests, which consists of a parallel RLC load, grid and the DG functioning in current controlled mode forming the equipment under test (EUT). Having a physical RLC load for this purpose results in several disadvantages in terms of cost and space requirements, especially when the rating of the DG under test increases. Also, tuning requirements of load parameters to suit the specifications of tests lead to additional design difficulties [6]. In addition, cooling arrangements are required because of the heat dissipation in the resistive branch.

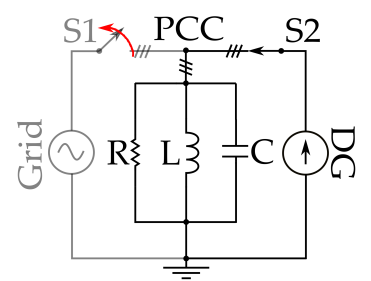

(a)

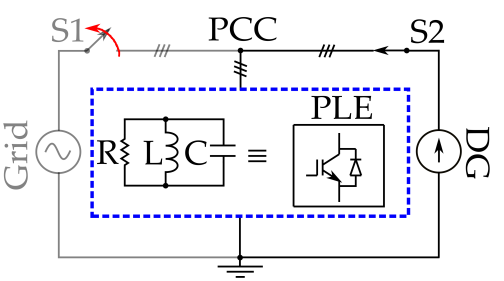

(b)

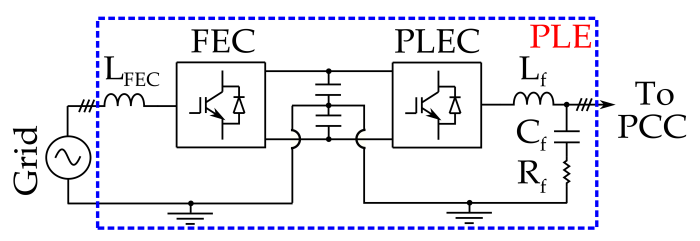

(c)

Fig. 1: (a) Equivalent circuit used for anti-islanding tests (b) Proposed impedance emulation technique where passive RLC load is replaced by PLE (c) Power circuit schematic of the passive load emulator (PLE) consisting of a front end converter (FEC) and the passive load emulation converter (PLEC). 


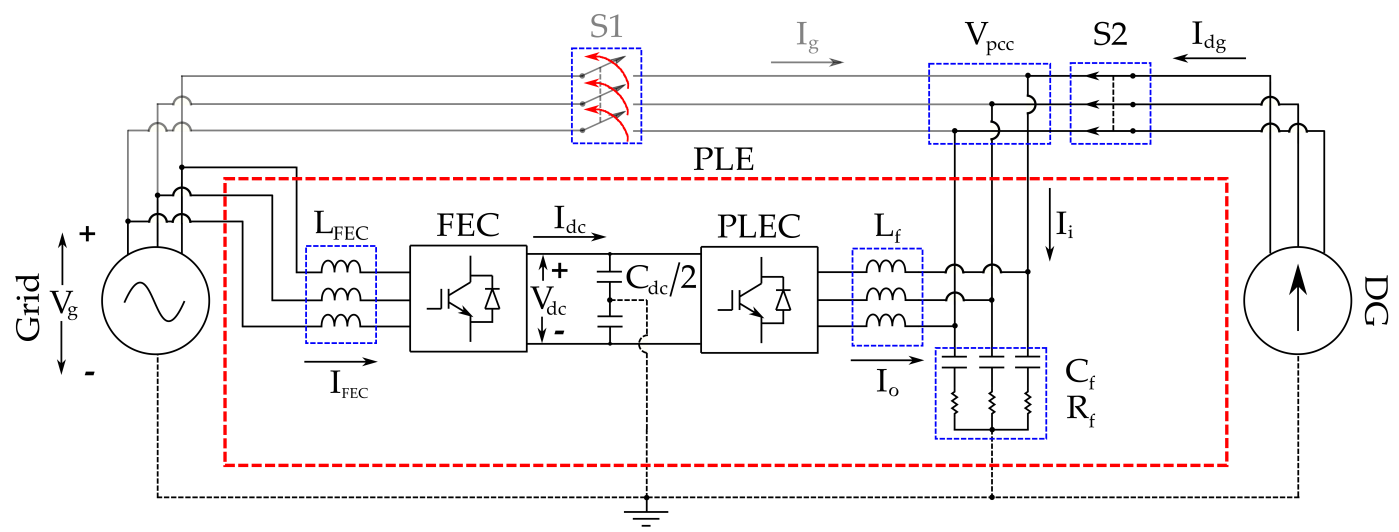

Fig. 2: Circuit schematic of the anti-islanding test-bench consisting of a grid, DG and the PLE.

On the other hand, power converter based impedance emulation technique brings several benefits such as lower cost, compact design and no power dissipation as the load is virtual [7]. Impedance emulation technique is often used with the help of different types of control strategies to replace the passive load present in the circuit [8]. All the control strategies basically focus on drawing a specific amount of power from the source, which can be a grid or a DG, such that the relationship between voltage and current at the terminal of the converter resembles the passive load [5].

In this paper, the passive load emulator (PLE) as shown in Fig. 1(b) is used for RLC load emulation. The setup consists of two $3 \phi$ converters connected in back-to-back configuration constituting a bidirectional front end converter (FEC) and the passive load emulation converter (PLEC), as shown in Fig. 1(c). Islanding tests are conducted in accordance with IEEE Std. 1547-2018, where the inductive and capacitive branches present in the parallel RLC load are compensated by each other. So, the proposed architecture controls the PLEC such that it draws only active power from the source during emulation. This active power drawn by PLEC is fed back to the grid by FEC, which leads to minimal power dissipation. A digital signal processor (DSP) platform is employed on which the proposed control is implemented. Different load parameters are obtained by appropriately changing the control parameter values in DSP.

\section{Proposed Control Architecture}

In the anti-islanding test-bench, initially both grid and DG are connected to PCC through switches S1 and S2 respectively as shown in Fig. 2. During islanding, S1 is opened while S2 remains closed [9]. The control architecture thus has to emulate the RLC load at first in the presence of grid and afterwards in its absence. Thus, the control architecture considers two operating modes of operation as follows.

\section{A. Impedance emulation during grid connected mode of op- eration :}

When a parallel RLC load is connected to the grid and DG both, it draws a specific amount of current and emulation is achieved by drawing the same amount of current using the current controlled $3 \phi$ PLEC. The proposed control architecture is shown in Fig. 3, where the PLEC is operated in current controlled mode using an inner current loop consisting of a proportional resonant controller $\left(G_{p r i}(s)\right)$ operating in stationary reference frame [10] and an outer reference generator block providing the required current reference derived from the sensed grid voltage. The bode plots of loop transfer function $\left(G_{\text {pri }}(s) \cdot G_{i}(s)\right)$ and closed loop transfer function of current loop are shown in Fig. 4.

During grid connected mode of operation, PLEC is connected to the grid which is a voltage source having very small series impedance. So, the capacitive filter does not provide any filtering. Thus for the current loop design calculations, capacitive filter can be ignored. But the capacitive filter contributes in achieving the desired capacitance in the emulated RLC load, therefore the total capacitance that should be synthesized by PLEC is correspondingly lower [5].

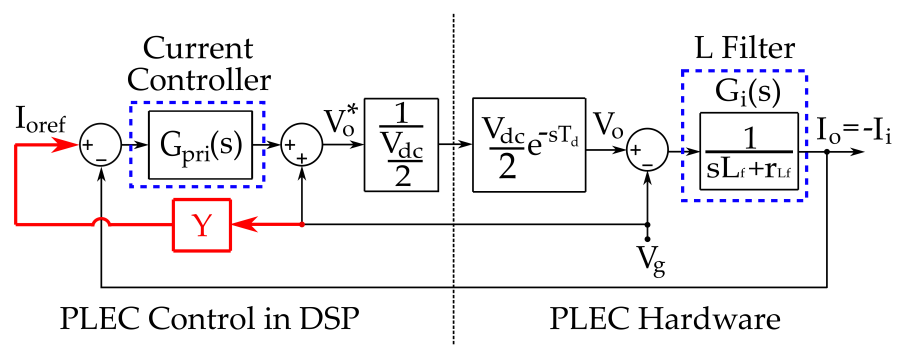

Fig. 3: Current loop and reference generator block during grid connected mode of operation.

From Fig. 3,

$G_{p r i}(s) \cdot G_{i}(s)=K_{p r i}\left(\frac{s^{2}+\frac{K_{i r i}}{K_{p r i}} s+\left(\omega_{o}\right)^{2}}{s^{2}+\left(\omega_{o}\right)^{2}}\right)\left(\frac{1}{s L_{f}+r_{L f}}\right)$

When $\omega=\omega_{g c i}$, taken as one-tenth of switching frequency,

$$
\begin{gathered}
\left|G_{p r i}(j \omega) \cdot G_{i}(j \omega)\right|_{\omega=\omega_{g c i}}=\frac{K_{p r i}}{\sqrt{\left(\omega_{g c i} L_{f}\right)^{2}+\left(r_{L f}\right)^{2}}} \\
\text { But }\left|G_{p r i}(j \omega) \cdot G_{i}(j \omega)\right|_{\omega=\omega_{g c i}}=1 \\
\Rightarrow K_{p r i}=\sqrt{\left(\omega_{g c i} L_{f}\right)^{2}+\left(r_{L f}\right)^{2}}
\end{gathered}
$$


Calculation of $K_{i r i}$ is done by assuming that a band of $\pm \triangle \omega_{o} \mathrm{rad} / \mathrm{sec}$ around $\omega_{o} \mathrm{rad} / \mathrm{sec}$ in magnitude plot of $G_{p r i}(s)$ always has a gain of $K_{i}$ [10].

Gain of $G_{p r i}(s)$ at $s=j\left(\omega_{o} \pm \triangle \omega_{o}\right)$ can be calculated using the assumption that $\frac{\triangle \omega_{0}}{\omega_{o}}<<1$.

$$
\begin{gathered}
\Rightarrow K_{i}=K_{p r i} \times \sqrt{1+\left(\frac{K_{i r i}}{2 K_{p r i} \times \Delta \omega_{o}}\right)^{2}} \\
\Rightarrow K_{i r i}=2 \triangle \omega_{o} \sqrt{\left(K_{i}\right)^{2}-\left(K_{p r i}\right)^{2}}
\end{gathered}
$$

For a parallel RLC load,

$$
Y^{*}=\frac{1}{R}+\frac{1}{s L}+s C
$$

So to emulate the load,

$$
\begin{aligned}
\frac{I_{i}}{V_{g}} & =Y^{*} \\
\Rightarrow \frac{I_{o}}{V_{g}}=\frac{-I_{i}}{V_{g}} & =\frac{Y G_{p r i}(s)}{s L_{f}+r_{L f}+G_{p r i}(s)}=-Y^{*}
\end{aligned}
$$

At $50 \mathrm{~Hz},\left|G_{\text {pri }}(s)\right|$ is very high,

$$
\Rightarrow Y=-Y^{*}
$$

TABLE I: Current controller parameters.

\begin{tabular}{|c|c|c|}
\hline S.N. & Parameter & Value \\
\hline 1 & $K_{\text {pri }}, K_{\text {iri }}$ & $31.4,596.5$ \\
\hline 2 & $\omega_{\text {gci }}$ & $2 \pi \times 1000 \mathrm{rad} / \mathrm{sec}$ \\
\hline 3 & Phase margin & $90.1^{\circ}$ \\
\hline
\end{tabular}

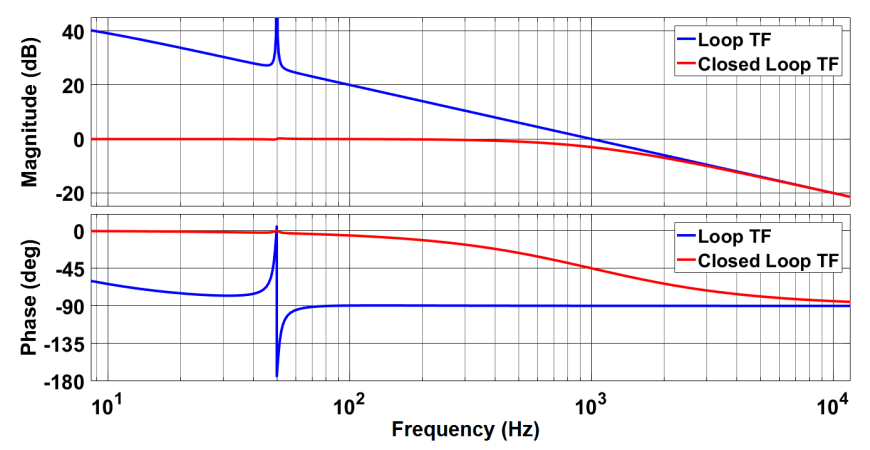

Fig. 4: Bode plots of loop transfer function and closed loop transfer function of current loop.

\section{B. Impedance emulation during islanded mode of operation :}

When a parallel RLC load is connected to the DG after grid disconnection, a specific amount of voltage is maintained at PCC and emulation is achieved by maintaining the same amount of voltage using the voltage controlled $3 \phi$ PLEC.

Two control strategies are proposed for RLC load emulation during islanded mode of operation. The first one is a two-loop control strategy and the second one is a single-loop control strategy as mentioned below.
1. Two-loop control : Desired voltage can be maintained at PCC by making use of the two-loop control architecture as shown in Fig. 5, where the PLEC is operated in voltage controlled mode using an inner voltage loop consisting of proportional resonant controller $\left(G_{p r v}(s)\right)$ and an outer reference generator block providing the required voltage reference derived from the sensed DG current. Voltage loop is designed to be four times slower than the current loop. So, for the voltage loop design calculations, current loop can be considered to be unity. The bode plots of loop transfer function $\left(G_{p r v}(s) \cdot G_{v}(s)\right)$ and closed loop transfer function of voltage loop are shown in Fig. 6.

Voltage loop comes into effect when islanding occurs. So, communication is required between grid side breaker and PLEC control. This is disadvantage of two-loop control strategy.

From Fig. 5,

$G_{p r v}(s) \cdot G_{v}(s)=K_{p r v}\left(\frac{s^{2}+\frac{K_{i r v}}{K_{p r v}} s+\left(\omega_{o}\right)^{2}}{s^{2}+\left(\omega_{o}\right)^{2}}\right)\left(\frac{1}{s C_{f}}+R_{f}\right)$

Calculation of $K_{i r v}$ is done by assuming that a band of $\pm \triangle \omega_{o} \mathrm{rad} / \mathrm{sec}$ around $\omega_{o} \mathrm{rad} / \mathrm{sec}$ in magnitude plot of $G_{p r v}(s)$ always has a gain of $K_{v}$.

Gain of $G_{p r v}(s)$ at $s=j\left(\omega_{o} \pm \triangle \omega_{o}\right)$ can be calculated using the assumption that $\frac{\triangle \omega_{0}}{\omega_{o}}<<1$.

$$
\begin{aligned}
\Rightarrow K_{v} & =K_{p r v} \times \sqrt{1+\left(\frac{K_{i r v}}{2 K_{p r v} \times \triangle \omega_{o}}\right)^{2}} \\
\Rightarrow K_{\text {irv }} & =2 \triangle \omega_{o} \sqrt{\left(K_{v}\right)^{2}-\left(K_{\text {prv }}\right)^{2}}
\end{aligned}
$$

As the bandwidth of voltage loop is low, $K_{v}>>K_{\text {prv }}$.

$$
\Rightarrow K_{i r v}=2 \triangle \omega_{o} \times K_{v}
$$

When $\omega=\omega_{g c v}$, taken as one-fourth of current loop bandwidth, that is one-fortieth of switching frequency,

$$
\begin{gathered}
\left|G_{p r v}(j \omega) \cdot G_{v}(j \omega)\right|_{\omega=\omega_{g c v}}=\left(\frac{K_{p r v}}{\left(\omega_{o}\right)^{2}-\left(\omega_{g c v}\right)^{2}}\right) \\
\left(\sqrt{\left(\left(\omega_{o}\right)^{2}-\left(\omega_{g c v}\right)^{2}\right)^{2}+\left(\frac{\omega_{g c v} K_{\text {irv }}}{K_{p r v}}\right)^{2}}\right)\left(\sqrt{\left(R_{f}\right)^{2}+\left(\frac{1}{\omega_{g c v} C_{f}}\right)^{2}}\right) \\
\text { But }\left|G_{p r v}(j \omega) \cdot G_{v}(j \omega)\right|_{\omega=\omega_{g c v}}=1
\end{gathered}
$$$$
\Rightarrow K_{p r v}=\sqrt{\frac{1}{\left(R_{f}\right)^{2}+\left(\frac{1}{\omega_{g c v} C_{f}}\right)^{2}}-\operatorname{bigg}\left(\frac{\omega_{g c v} K_{i r v}}{\left(\omega_{o}\right)^{2}-\left(\omega_{g c v}\right)^{2}}\right)^{2}}
$$

For a parallel RLC load,

$$
\text { Impedance }=Z^{*}=R\|s L\| \frac{1}{s C}
$$




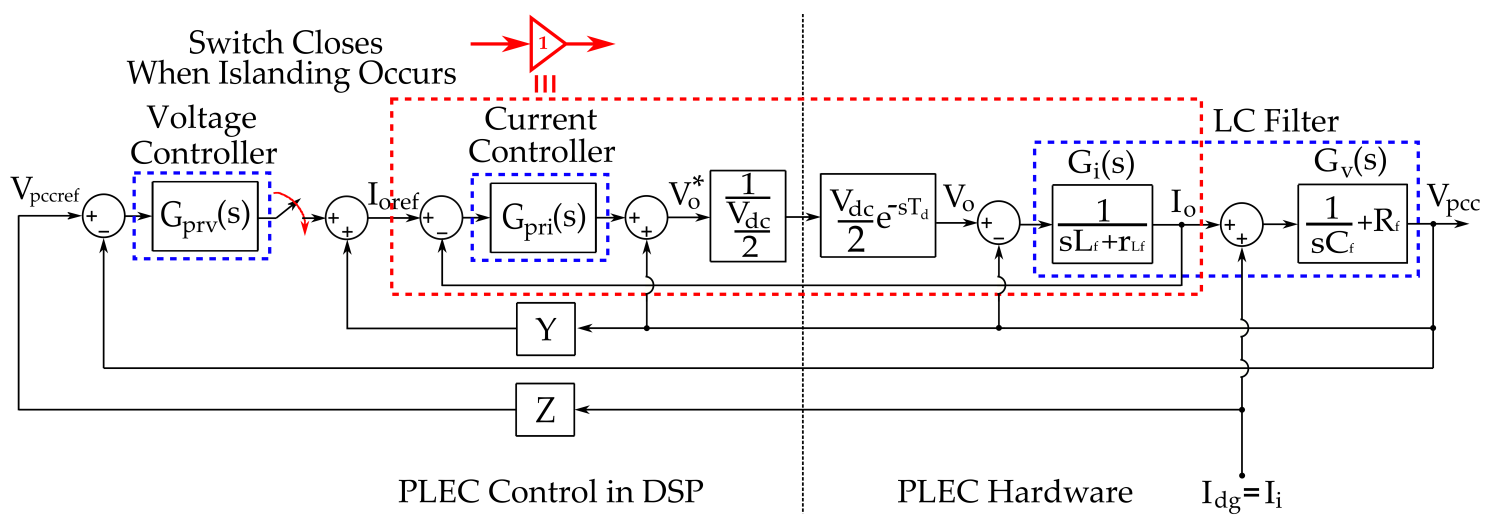

Fig. 5: Two-loop control strategy showing voltage loop and reference generator block during islanded mode of operation.

So, to emulate the load,

$$
\begin{aligned}
& \frac{V_{p c c}}{I_{d g}}=Z^{*} \\
\Rightarrow \frac{V_{p c c}}{I_{d g}}= & \frac{Z G_{p r v}(s)\left(\frac{1}{s C_{f}}+R_{f}\right)}{1+G_{p r v}(s)\left(\frac{1}{s C_{f}}+R_{f}\right)}=Z^{*}
\end{aligned}
$$

At $50 \mathrm{~Hz},\left|G_{p r v}(s)\right|$ is very high,

$$
\Rightarrow Z=Z^{*}
$$

TABLE II: Voltage controller parameters.

\begin{tabular}{|c|c|c|}
\hline S.N. & Parameter & Value \\
\hline 1 & $K_{p r v}, K_{i r v}$ & $0.015,6.28$ \\
\hline 2 & $\omega_{g c v}$ & $2 \pi \times 250 \mathrm{rad} / \mathrm{sec}$ \\
\hline 3 & Phase margin & $78.86^{\circ}$ \\
\hline
\end{tabular}

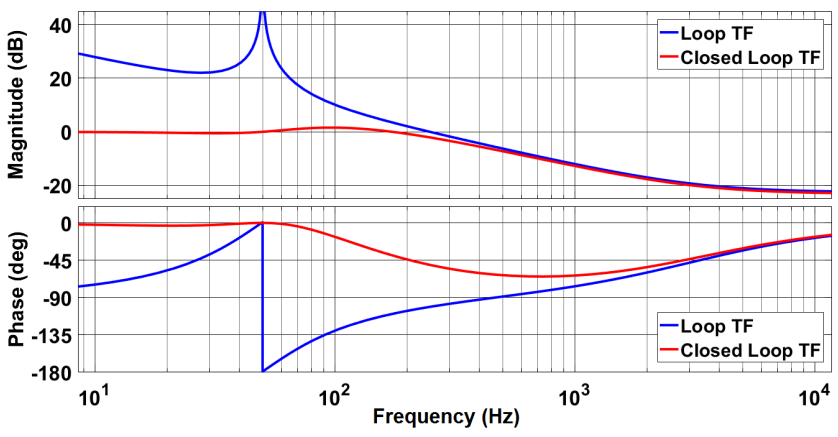

Fig. 6: Bode plots of loop transfer function and closed loop transfer function of voltage loop.

2. Single-loop control : Desired voltage is maintained at PCC by making use of the existing current loop mentioned in grid connected mode as shown in Fig. 7(a). So the current in grid connected mode and the voltage in islanded mode are controlled using a single control loop.
As single control loop is used for both grid connected mode and islanded mode, the control strategy needs no communication from grid side breaker regarding time of islanding. This is advantageous over two-loop control strategy.

From Fig. 7(a),

$$
\frac{V_{p c c}}{I_{d g}}=\frac{\left(\frac{1}{s C_{f}}+R_{f}\right)}{1-\left(\frac{1}{s C_{f}}+R_{f}\right)\left(\frac{G_{p r i}(s) \times Y}{s L_{f}+r_{L f}+G_{p r i}(s)}\right)}
$$

At $50 \mathrm{~Hz},\left|G_{p r i}(s)\right|$ is very high,

$$
\Rightarrow \frac{V_{p c c}}{I_{d g}}=\frac{\left(\frac{1}{s C_{f}}+R_{f}\right)}{1-\left(\frac{1}{s C_{f}}+R_{f}\right) \times Y}
$$

But $Y=-Y^{*}$,

$$
\Rightarrow \frac{V_{p c c}}{I_{d g}}=\frac{\left(\frac{1}{s C_{f}}+R_{f}\right)}{1+\left(\frac{1}{s C_{f}}+R_{f}\right) \times Y^{*}}
$$

But $Z^{*}=\frac{1}{Y^{*}}$,

$$
\Rightarrow \frac{V_{p c c}}{I_{d g}}=\frac{\left(\frac{1}{s C_{f}}+R_{f}\right) \times Z^{*}}{\left(\frac{1}{s C_{f}}+R_{f}\right)+Z^{*}}
$$

Relationship between $V_{p c c}$ and $I_{d g}$ gives the impedance equivalent to parallel combination of capacitive filter and $Z^{*}$ as shown in Fig. 7(b). So, the PLEC has to emulate lower value of capacitance in the emulated RLC load as mentioned in grid connected mode of operation.

Bode plots of the emulated impedance with different bandwidth values of the current loop are shown in Fig. 8. The bode plots of the emulated impedance close to $50 \mathrm{~Hz}$ frequency are shown in Fig. 9, where it can be observed that the accuracy of the emulated impedance improves as the bandwidth increases. 


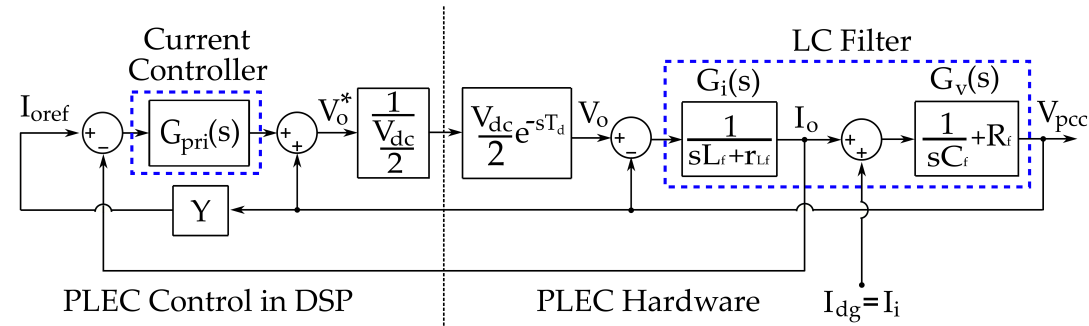

(a)

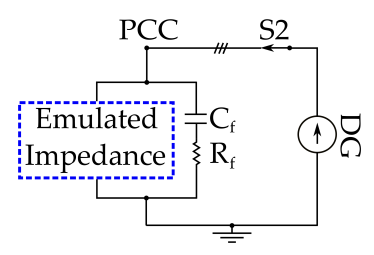

(b)

Fig. 7: (a) Single-loop control architecture, (b) Effect of capacitive filter in impedance emulation.

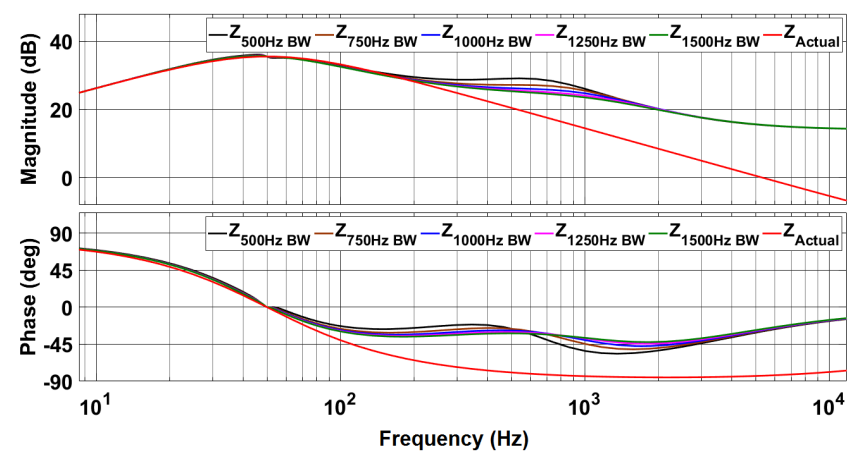

Fig. 8: Bode plots of the emulated RLC load with different bandwidth values and actual passive load with $\mathrm{R}=60 \Omega, \mathrm{L}=0.34$ $\mathrm{H}, r_{L}=1 \Omega, \mathrm{C}=30 \mu \mathrm{F}, r_{C}=0.1 \Omega$.

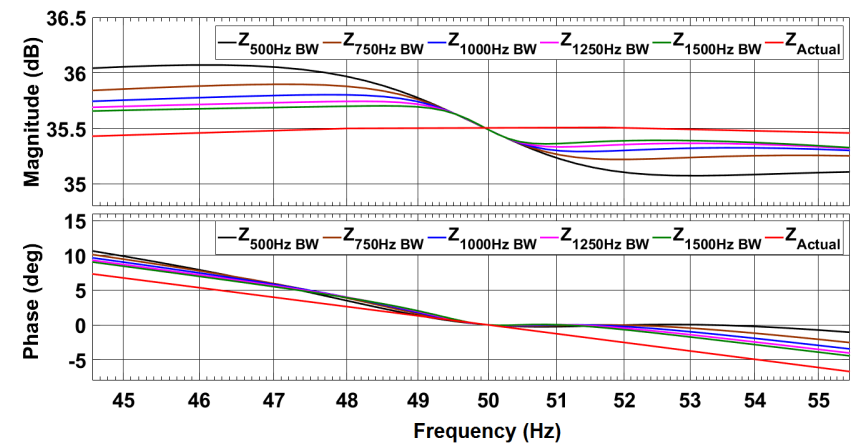

Fig. 9: The bode plots of the emulated RLC load close to $50 \mathrm{~Hz}$ frequency with different bandwidth values and actual passive load with $\mathrm{R}=60 \Omega, \mathrm{L}=0.34 \mathrm{H}, r_{L}=1 \Omega, \mathrm{C}=30 \mu \mathrm{F}, r_{C}=0.1 \Omega$.

\section{Simulation And ExPERIMENTAL Results}

Simulations and experiments are done in accordance with IEEE Std. 1547-2018. Parameters of the proposed antiislanding test-bench are mentioned in Table III.

Fig. 10 shows the step change of input current of the PLEC due to step change of emulated resistance from $120 \Omega$ to $60 \Omega$ during grid connected mode of operation. It can be observed that the current tracks the change instantaneously because of the high current loop bandwidth.
TABLE III: Anti-islanding test-bench parameters.

\begin{tabular}{|c|c|c|}
\hline S.N. & Parameter & Value \\
\hline 1 & PLEC power rating & $2.64 \mathrm{kVA}$ \\
\hline 2 & Grid voltage rating & $230 \mathrm{~V}$ \\
\hline 3 & DG current rating & $3.8 \mathrm{~A}$ \\
\hline 4 & Grid and DG power factor & 1 \\
\hline 5 & DC link voltage & $800 \mathrm{~V}$ \\
\hline 6 & Switching frequency & $10 \mathrm{kHz}$ \\
\hline 7 & Filter parameters & $L_{f}=5 \mathrm{mH}, C_{f}=10 \mu \mathrm{F}, R_{f}=5 \Omega$ \\
\hline 8 & Load parameters & $\mathrm{R}=60 \Omega, \mathrm{L}=0.34 \mathrm{H}, r_{L}=1 \Omega$, \\
& & $\mathrm{C}=30 \mu \mathrm{F}, r_{C}=0.1 \Omega$ \\
\hline 9 & Load quality factor & 1 \\
\hline
\end{tabular}

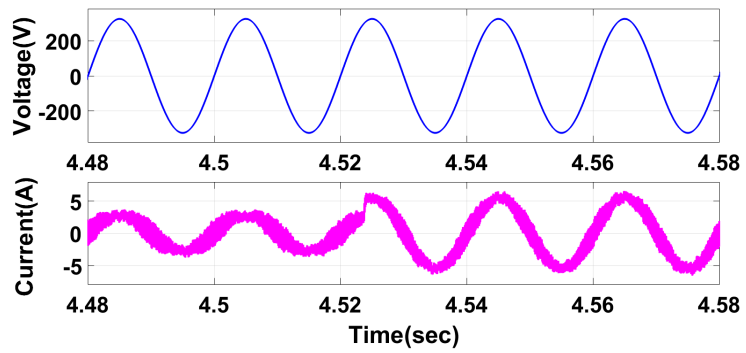

(a)

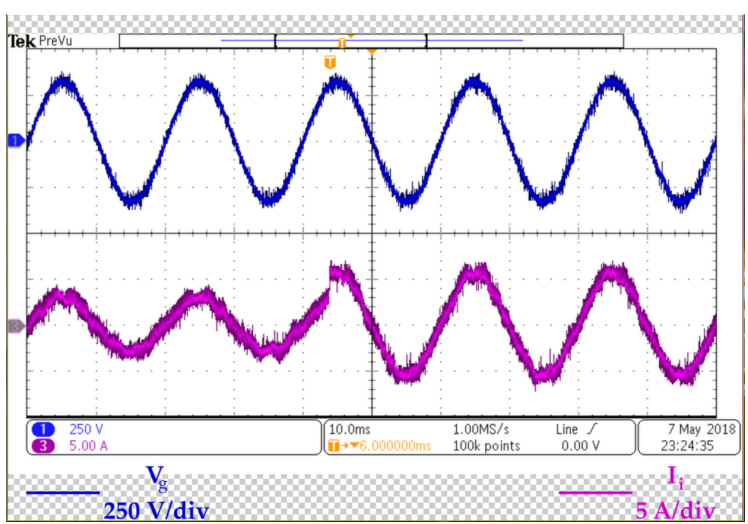

(b)

Fig. 10: (a) Simulation and (b) Experimental results of R phase grid voltage and input current of PLEC which show the step change of current from $0.5 \mathrm{pu}$ to $1 \mathrm{pu}$ due to step change of emulated resistance from $120 \Omega$ to $60 \Omega$ during grid connected mode of operation. 


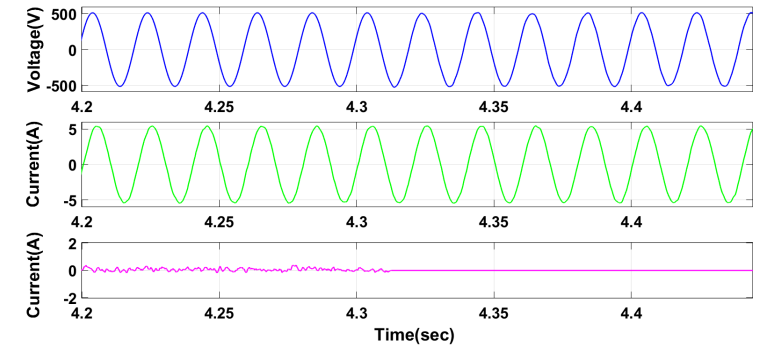

(a)

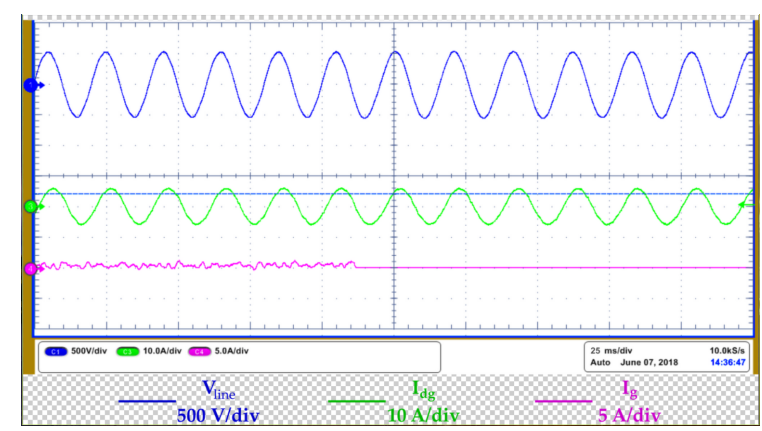

(b)

Fig. 11: (a) Simulation and (b) Experimental results of line voltage at PCC (R-Y), DG current and grid current which show the transition from grid connected mode to islanded mode.

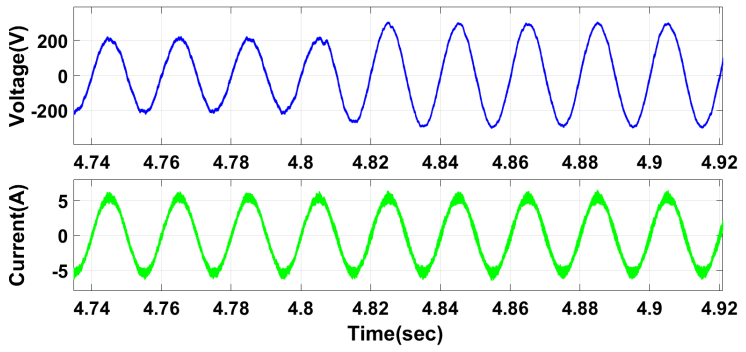

(a)

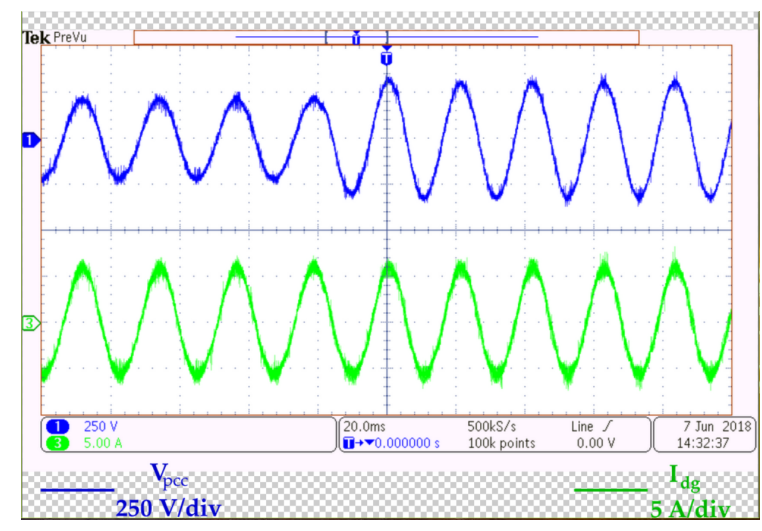

(b)

Fig. 12: (a) Simulation and (b) Experimental results of $\mathrm{R}$ phase voltage at PCC and DG current which show the step change of voltage from $0.7 \mathrm{pu}$ to $1 \mathrm{pu}$ due to step change of emulated resistance from $42 \Omega$ to $60 \Omega$ during islanded mode of operation.
Fig. 11 shows the transition from grid connected mode of operation to islanded mode of operation. It can be observed that the grid current is completely zero after islanding because of opening of the grid side breaker. Also, there is no effect of islanding on the DG current and voltage at PCC. So, the control architecture emulates the RLC load properly during grid connected mode as well as islanded mode.

Fig. 12 shows the step change of R phase voltage at PCC due to step change of emulated resistance from $42 \Omega$ to $60 \Omega$ during islanded mode of operation. It can be observed that the voltage tracks the change instantaneously for both the simulation and experiment as the DG current is held constant.

\section{CONClusions}

Power converter based passive RLC load emulation is proposed for anti-islanding tests. Two control architectures are proposed that emulate the load in both grid connected mode and islanded mode. Emulation is verified at $50 \mathrm{~Hz}$ as well as over a wide range of frequency with the help of simulations. Experiments are done on $3 \phi, 5 \mathrm{kVA}$ hardware setup along with a current controlled grid tied inverter that verify the high performance achieved by the proposed passive load emulator.

\section{REFERENCES}

[1] J. Driesen and F. Katiraei, "Design for distributed energy resources," in IEEE Power and Energy Magazine, vol. 6, no. 3, pp. 30-40, May-June 2008.

[2] R. A. Walling and N. W. Miller, "Distributed generation islandingimplications on power system dynamic performance," IEEE Power Engineering Society Summer Meeting, Chicago, IL, USA, 2002, pp. 9296 vol.1.

[3] Zhihong Ye, A. Kolwalkar, Yu Zhang, Pengwei Du and Reigh Walling, "Evaluation of anti-islanding schemes based on nondetection zone concept," in IEEE Transactions on Power Electronics, vol. 19, no. 5, pp. 1171-1176, Sept. 2004.

[4] R. Sgarbossa, S. Lissandron, P. Mattavelli, R. Turri and A. Cerretti, "Analysis of load-induced unintentional islanding in Low Voltage grids with PV generators," 2014 IEEE 15th Workshop on Control and Modeling for Power Electronics (COMPEL), Santander, 2014, pp. 1-8.

[5] L. Dalla Santa, T. Caldognetto, P. Magnone and P. Mattavelli, "Implementation of an active RLC load for unintentional islanding test," 2016 18th European Conference on Power Electronics and Applications (EPE'16 ECCE Europe), Karlsruhe, 2016, pp. 1-8.

[6] D. Venkatramanan and V. John, "Modeling and analysis of passive networks using dynamic phasors for study of islanded inverters," 2017 IEEE Transportation Electrification Conference (ITEC-India), Pune, 2017, pp. 1-6.

[7] T. Caldognetto, L. D. Santa, P. Magnone and P. Mattavelli, "Power Electronics Based Active Load for Unintentional Islanding Testbenches," in IEEE Transactions on Industry Applications, vol. 53, no. 4, pp. 38313839, July-Aug. 2017.

[8] F. de Bosio, M. Pastorelli, L. A. d. S. Ribeiro, M. S. Lima, F. Freijedo and J. M. Guerrero, "Current control loop design and analysis based on resonant regulators for microgrid applications," IECON 2015 41st Annual Conference of the IEEE Industrial Electronics Society, Yokohama, 2015, pp. 005322-005327.

[9] F. Belloni, P. Groppelli, C. Chiappa, R. Chiumeo and C. Gandolfi, "Test of anti-islanding protections according to IEC 62116: An experimental feasibility assessment," Power Engineering Conference (UPEC), 2013 48th International Universities', Dublin, 2013, pp. 1-6.

[10] A. Ghoshal and V. John, "A controller design method for 3 phase 4 wire grid connected vsi with lcl filter," in Sadhana, vol. 40, no. 5, pp. 1481-1499, 2015.

[11] D. Venkatramanan, Anil Adapa and V. John, "Design and comparative study of discrete and module-based IGBT power converters," in Sadhana, vol. 42, no. 8, pp. 14011409, August 2017. 